\title{
Electronic Raman scattering as a probe for investigating interactions between impurities in silicon
}

\author{
N. Stavrias, P. G. Spizzirri, ${ }^{*}$ and S. Prawer $^{\dagger}$ \\ School of Physics, University of Melbourne, Parkville VIC 3010, Australia
}

(Dated: October 5, 2018)

\begin{abstract}
Electronic Raman scattering (ERS) is investigated as a probe for interactions between impurities in silicon. We report ERS measurements of donors (P, Sb and As) and acceptors (B) at various concentrations, and measurements at various illumination wavelengths. The difference between above and below indirect band gap measurement is discussed in terms of the difficulties of using ERS as a localised probe. We extend the previous literature on impurity interactions of Si:P in the bulk to include $\mathrm{Sb}$ and $\mathrm{B}$ and demonstrate that the perturbation of the observed ERS transition energy resulting from wavefunction overlap of nearest neighbours is opposite for donors and acceptors. Finally we model the magnitude of the shift to the first order as a function of the mean impurity atom separation.
\end{abstract}

This is the author manuscript accepted for publication and has undergone full peer review but has not been through the copyediting, typesetting, pagination and proofreading process, which may lead to differences between this version and the Version of Record. Please cite this article as doi: $10.1002 /$ jrs.5543 


\section{Contents}

I. Introduction 2

II. Experimental 4

III. Results and Discussion 6

A. NIR Raman Spectra 6

B. Visible Raman Spectra 8

1. Excitation wavelength dependence and resonance 8

C. Impurity Concentration Effects 10

1. Acceptor interactions 13

2. ERS peak energy shift 14

$\begin{array}{ll}\text { IV. Conclusion } & 15\end{array}$

$\begin{array}{ll}\text { Acknowledgments } & 16\end{array}$

$\begin{array}{ll}\text { References } & 16\end{array}$

\section{INTRODUCTION}

As semiconductor device features continue to shrink, the precise placement, separation and interaction of dopant atoms can significantly influence the electrical properties of devices. It is therefore important to understand the wavefunction of dopant states, both isolated and perturbed by a nearby state. An elegant experimental proposal to investigate dopant interactions was reported by Koiller et al. ${ }^{1}$ who suggested that electronic micro-Raman scattering (ERS) spectroscopy could be used to directly probe low lying donor states in an actual silicon device with micron scale resolution and potentially, few donor sensitivity. Key to this proposal was the use of UV excitation to achieve a local resonance that would provide enough signal enhancement to allow the detection of a single (or few dopants) within the measurement volume (e.g. a semiconductor transistor channel), and measurement of any perturbations to the dopant wavefunction. Such a measurement would also in principal permit the direct observation and quantification of the exchange parameter for two or more 
coupled dopants in an active device, an important parameter in Si quantum information processing $^{2}$. In this paper we report on our investigations of dopant interactions in bulk silicon and the challenges in scaling this technique down to few impurity measurements using ERS.

The Raman technique is based upon the inelastic scattering of light and is commonly used to study discrete molecular vibrational states and collective modes of vibrational states ${ }^{3}$. It can also be used to directly observe parity forbidden electronic transitions in semiconducting crystals. ERS was first proposed for studying paramagnetic rare earth ions ${ }^{4}$, and has been used extensively to study direct band gap semiconductors ${ }^{5,6}$ where significant ERS intensity enhancement has been observed when the excitation wavelength approaches the direct bandgap energy. While ERS has recently been neglected as a technique for studying dopants in silicon, the original ERS studies have provided a great deal of information about donors and acceptors such as: their energy levels ${ }^{7}$, the direct observation of wavefunction overlap in high concentration ensembles and the metal-insulator transition ${ }^{8}$, as well as Zeeman splitting and stress effects on impurity states ${ }^{9}$. Studies of other Group-IV semiconductors, such as $\mathrm{N}$ in $\mathrm{SiC}^{10}$ and $\mathrm{As}$ in $\mathrm{Ge}^{11,12}$ as well as $\mathrm{B}$ in diamond ${ }^{13}$ have shown similar ERS effects. Interestingly, all these studies were performed with excitation energies less than the indirect band-gap of the host semiconductor to maximise the penetration depth of the laser, noting only one study of acceptors in Si where ERS has been observed with light above but still close to the indirect band gap ${ }^{14}$. The other excitation range which has produced ERS from donors in silicon is in the $\mathrm{THz} /$ far-IR where stimulated emission of $\mathrm{THz}$ light from the impurity electronic transitions has been realised ${ }^{15,16}$.

In silicon, the $1 s$ donor states are split due to valley-orbit coupling into a ground state $1 s\left(A_{1}\right)$ singlet and excited doublet $1 s(E)$ and triplet $1 s\left(T_{2}\right)$ states. The binding energy of the ground state and the relative energy differences of the split levels are greatly influenced by the ionic core of the donor atom ${ }^{17}$ with the $1 s\left(A_{1}\right)$ state bound more tightly than the other levels. The chemical species of the donor affects the energy levels of these states, called the chemical shift, making the ERS technique suitable for dopant identification. The ERS spectral feature for donors arises from a transition between the $1 s\left(A_{1}\right)$ and $1 s(E)$ levels. For phosphorus donors in silicon ${ }^{7}$, the energy of the ERS transition is $13.1 \mathrm{meV}$ which gives rise to an optical ERS transition at $105 \mathrm{~cm}^{-1}$.

ERS from acceptors in silicon involves a transition between the $1 s$ like ground states, 
$\Gamma_{8}^{+}\left(1 S p_{3 / 2}\right)$ and its partner state $\Gamma_{7}^{+}\left(1 S p_{1 / 2}\right)$, associated with the spin-orbit split valence band ${ }^{18,19}$. The ERS transition for B in Si has been observed at $23.4 \mathrm{meV}\left(184 \mathrm{~cm}^{-1}\right)$, and for deeper acceptors the observed ERS transition tends to smaller energies ${ }^{14}$. Higher level even parity acceptor orbital states in $\mathrm{Si}$ :B have also been observed via ERS with the use of an excitation source below the energy of the bound excitons, thus removing the bound exciton lines from the spectrum ${ }^{20}$.

At donor concentrations where neighbouring donor ground state wavefunctions start to overlap and interact, the donor ERS peak was observed to broaden and shift to lower energies $^{8,12}$. This effective shift to lower energies was interpreted as resulting from donor electron wavefunction overlap leading to electronic exchange coupling between nearest $\mathrm{P}$ neighbouring atoms. When donor electrons are shared between two or more donors, less time is spent close to their ionic cores, effectively decreasing the influence of the chemical shift. As a consequence, the $1 s\left(A_{1}\right)$ ground state shifts in energy towards the excited donor states and the ERS peak is observed at lower energies. The distribution of interacting donor separations results in a broadened peak. The effect of increasing impurity concentration as studied by ERS in Si has only been reported for P donors, where the formation of the impurity band at the metal-insulator transition (MIT) was observed by the disappearance of a distinct ERS peak into a broad continuum.

This work revisits ERS as a technique for studying donors and acceptors in silicon over a wide range of doping densities. We comment on the observed overlap of ERS, phonon Raman scattering, and photoluminescence (PL) features in the near infra-red (NIR) spectral window. We observe the broadening and shift to lower energies of the donor ERS peaks as a function of dopant concentration, and for the first time we report the broadening and shift to higher energies of the boron ERS peak with increasing concentration. The magnitude of the shifts in energy observed follow that expected from wavefunction overlap of neighbouring impurity states. We also report on attempts to exploit the resonance in the ERS transition cross section by using visible wavelength illumination.

\section{EXPERIMENTAL}

Measurements were performed on commercially sourced, single crystal silicon wafers of thickness between 250 to $700 \mu \mathrm{m}$. Table I provides a list of the samples which include 
boron acceptors and phosphorus, antimony or arsenic donors over a wide concentration range. Measurements were made on the polished top surface of the wafer without further treatment, with the incoming and collected light parallel to the $<100>$ direction.

Near infra-red (NIR) Raman experiments were performed using a Renishaw Invia Reflex confocal micro-Raman spectrometer equipped with a $0.25 \mathrm{~m}$ spectrograph and fitted with a liquid nitrogen cooled, Princeton Instruments OMA V InGaAs array detector. Measurements were performed in backscattering geometry. The instrument had an operational spectral range of $0.8-1.7 \mu \mathrm{m}$ and the excitation source was a line narrowed Nd:YAG laser operating at $1064 \mathrm{~nm}$. Microscope optics were all optimized for operation in the NIR and the sample was illuminated through a 0.4 N.A., $20 \times$ long working distance microscope objective. The spectral resolution of the instrument was approximately $3 \mathrm{~cm}^{-1}$ when using an $830 \mathrm{~g} / \mathrm{mm}$ grating as determined from the full width at half maximum of a neon emission line. An edge blocking filter supplied by Renishaw permitted measurements from $55 \mathrm{~cm}^{-1}$, suitable for the collection of the Stokes ERS signal from both donors and acceptors.

Visible excitation wavelength Raman measurements were performed using either: (i) the same Renishaw Invia Reflex instrument reconfigured for visible wavelength operation employing a frequency doubled Nd:YAG laser operating at $532 \mathrm{~nm}$, a $2400 \mathrm{~g} / \mathrm{mm}$ grating and a TE cooled, back illuminated silicon CCD detector or (ii) a Jobin Yvon Dilor XY microRaman spectrometer operating in triple additive mode with an argon ion laser operating at either 488.0 or $514.5 \mathrm{~nm}$, and with a liquid nitrogen cooled silicon CCD detector. In both cases, measurements were performed in a backscattering geometry. The notch filters on the Renishaw system allowed measurements to be performed above $120 \mathrm{~cm}^{-1}$ making it suitable for observing B acceptor transitions while the Dilor system was well suited to P donor measurements with a spectral range starting below $50 \mathrm{~cm}^{-1}$.

All samples were housed in a Janis ST-500 liquid helium flow cryostat designed for microscopy measurements and were attached to the stage using conductive silver paste to assist with thermal transfer in vacuum.

All NIR measurements were obtained using $100 \mathrm{~mW}$ of the $1064 \mathrm{~nm}$ laser (measured before the objective lens). Under these conditions, laser heating above the base temperature of the cryostat $\left(T_{\text {cryo }}=4.2 \mathrm{~K}\right)$ was observed and quantified using changes to the photoluminescence $(\mathrm{PL})$ emission lines arising from excitonic states, with sample temperatures estimated to be around 15-20 K. Details of the temperature estimation can be found in 
Figure S1 (Supporting Information). In the case of visible-light excited ERS measurements, much lower laser powers were employed (generally $<10 \mathrm{~mW}$ ).

Raman features have been reported as wavenumber shifts (the enegy difference between the laser energy and the observed line position) and PL contributions as absolute wavenumber. The spectra are plotted with both these units on the figure. The measured positions of the spectral features of interest are consistent with the previous literature ${ }^{8,21,22}$. See Table S1 (Supporting Information) for a list of spectral features.

\section{RESULTS AND DISCUSSION}

\section{A. NIR Raman Spectra}

Figure 1 shows the spectrum from a $1.3-1.9 \times 10^{16} \mathrm{~cm}^{-3}$ phosphorus doped silicon sample measured using NIR excitation. The spectrum is composed of phononic and electronic Raman features, as well as photoluminescence transitions. The use of the $1064 \mathrm{~nm}(1.1654 \mathrm{eV}$, $9398.5 \mathrm{~cm}^{-1}$ ) excitation source brings all these transitions into a common spectral range; a consequence of being near to the indirect band gap for $\mathrm{Si}\left(1.17 \mathrm{eV}, 9436.7 \mathrm{~cm}^{-1}\right)$. Bound exciton luminescence is observed due to the fact that while the laser energy is less than the indirect band gap of $\mathrm{Si}$ it is still above the no phonon free exciton edge energy $\left(1.1545 \mathrm{eV}^{25}\right)$.

The main features of the spectrum include the electronic Raman scattering transition between the phosphorus donor $1 s\left(A_{1}\right) \rightarrow 1 s(E)$ levels at $105 \mathrm{~cm}^{-1}$. The no phonon $\mathrm{P}_{\mathrm{NP}}$, transverse acoustic $\mathrm{P}_{\mathrm{TA}}$, and transverse optic $\mathrm{P}_{\mathrm{TO}}$ phonon replica of the bound exciton luminescence transitions were also observed. The strong transition at $524 \mathrm{~cm}^{-1}$ is due to Raman scattering from the zone centre transverse optical (TO) phonon of silicon. The shoulder on the right hand side of this peak is a combination of the TO and LO (longitudinal optical) replica of the silicon free exciton (FE) luminescence. Second order (phonon) Raman scattering is also just evident above the background noise with the $2 \times \mathrm{TA}$ (transverse acoustic) phonon line at $305 \mathrm{~cm}^{-1}$ being the most prevalent feature.

A spectrum measured from B doped Si $\left(9.5 \times 10^{15}-1.5 \times 10^{16} \mathrm{~cm}^{-3}\right)$ is also shown in Figure 1, where the dominant transitions are labelled. The B ERS peak was clearly observed at $184 \mathrm{~cm}^{-1}$. The photoluminescence lines $\mathrm{B}_{\mathrm{TA}}$ and $\mathrm{B}_{\mathrm{TO}}$ are evident, while the much weaker $\mathrm{B}_{\mathrm{NP}}$ transition was not observed ${ }^{22}$. The free exciton and phonon Raman features from the 


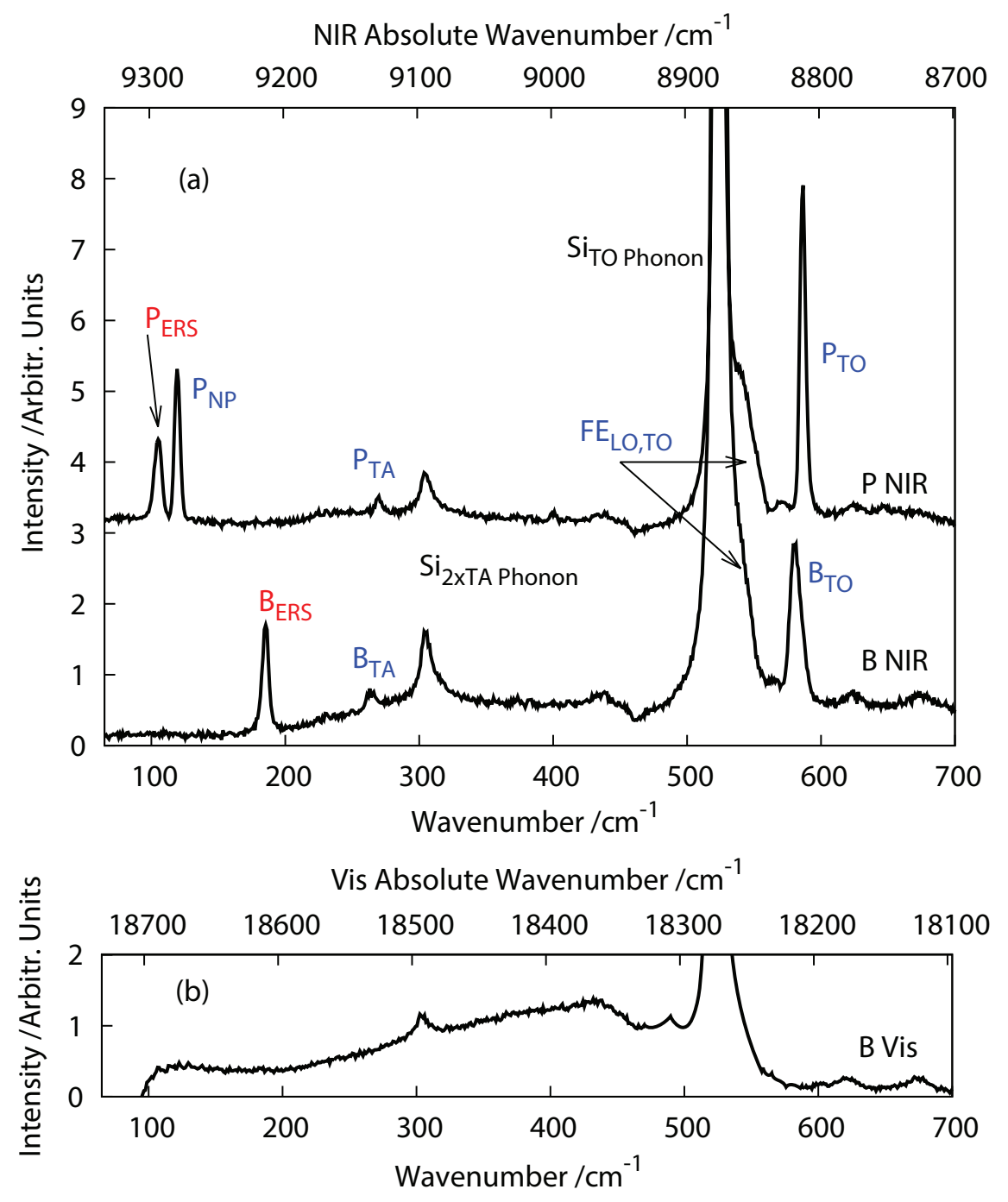

FIG. 1: (a) Raman spectrum of Si samples using $1064 \mathrm{~nm}$ excitation, P NIR: Si doped with $\sim 1.6 \times 10^{16} \mathrm{~cm}^{-3} \mathrm{P}$ donors, and B NIR: Si sample doped with $\sim 1 \times 10^{16} \mathrm{~cm}^{-3} \mathrm{~B}$ acceptors. Spectra scaled for comparison and displaced vertically for clarity. (b) B Vis: Raman spectrum from Si doped with $\sim 2.5 \times 10^{17} \mathrm{~cm}^{-3} \mathrm{~B}$ acceptors using $532 \mathrm{~nm}$ excitation $(6 \mathrm{~mW}, 100 \mathrm{~s}$ integration time, $\left.T_{\text {cryo }}=4.2 \mathrm{~K}\right)$. For peak labels see text and Table S1. ERS peaks are labelled in red, PL in blue and phonon Raman in black. Note the NIR and visible spectra can be directly compared in wavenumber units but not in absolute wavenumber.

host silicon were the same as those in the Si:P sample. 


\section{B. Visible Raman Spectra}

In contrast to the NIR measurements, data obtained using visible excitation (488 nm, $514.5 \mathrm{~nm}$ and $532 \mathrm{~nm}$ ) did not display any ERS transitions. Figure 1 includes a typical spectrum from a sample containing $2.2-2.7 \times 10^{17} \mathrm{~cm}^{-3} \mathrm{~B}$ acceptors. Note that there is no sign of the B ERS transition at $184 \mathrm{~cm}^{-1}$, and only the phonon scattering spectrum is observed. ERS measurements in the visible were also performed on samples with $\mathrm{P}$ donors over a large range of laser illumination intensities, photon integration times and the use of both $488 \mathrm{~nm}$ and $514 \mathrm{~nm}$ excitation, however once again no ERS transitions were observed. It is also important to note that the visible wavelength and NIR spectra can be directly compared in units of wavenumber but not in absolute wavenumber.

\section{Excitation wavelength dependence and resonance}

Previous measurements used below band gap excitation to maximise scattering volume. For silicon, excitations above the indirect band gap (visible and UV light) are strongly absorbed $^{26}$, reducing the scattering volume. This would provide an advantage for focusing on small numbers of impurities. With the increase in instrumentation light collection since the first ERS measurements were made 40 or so years ago, the smaller amount of scattered light might still be detectable, especially in the visible and UV.

The contribution to the scattering cross section from the scattering volume (depth), using optical absorption data from $\operatorname{Ref}^{26}$ is shown with the solid line in Figure 2. The large reduction in the cross section above the indirect gap at $1.17 \mathrm{eV}$ can clearly be seen. For the NIR laser used $(1.1654 \mathrm{eV})$ the absorption depth is $1 \mathrm{~mm}$, for the visible $(514 \mathrm{~nm}, 2.4121 \mathrm{eV})$ this drops to $1 \mu \mathrm{m}$, and in the $\mathrm{UV}(3.4 \mathrm{eV})$ to $10 \mathrm{~nm}$.

Exploiting a resonance in the ERS scattering cross section by using illumination energy approaching the direct band gap of $\mathrm{Si}(3.4 \mathrm{eV})^{1}$, could also improve detection. The resonant enhancement is part of the differential scattering cross section. For electronic Raman scattering from a donor in silicon with an electron in an initial state $S_{0}$ scattered to a final state $S_{f}$, and ignoring the absorption of light by the crystal, the differential cross section 
follows ${ }^{8}$ :

$$
\begin{aligned}
\frac{d \sigma(0 \rightarrow f)}{d \Omega_{R}}= & r_{0}^{2} \frac{\omega_{R}}{\omega_{L}} R_{12}^{2}\left(\mu_{\|}-\mu_{\perp}\right)^{2} \\
& \times\left|\sum_{j=1}^{6} \alpha_{j}^{(f) *} \alpha_{j}^{(0)}\left(\vec{\eta}_{L} \cdot \hat{\eta}_{j}\right)\left(\vec{\eta}_{R} \cdot \hat{\eta}_{j}\right)\right|^{2}
\end{aligned}
$$

where $r_{0}=e^{2} / m c^{2}$ is the classical radius of the electron, $\omega_{L}$ and $\omega_{R}$ the wavenumber of the incoming and scattered light with $\vec{\eta}_{L}$ and $\vec{\eta}_{R}$ their polarization, $\hat{\eta}_{j}$ the unit vector along the direction of the $j$-th conduction band valley, and $\mu_{\|}$is the parallel component of the effective mass tensor and $\mu_{\perp}$ the perpendicular component, which arise due to the anisotropy of the conduction band with $\mu=m^{*-1}$. The $\alpha_{j}$ 's are terms which indicate the symmetries of the states $^{27}$, and the products of these with the polarization and orientation set the selection rules for the scattering. Note the resonant enhancement factor:

$$
R_{12}=\frac{E_{G}^{2}}{E_{G}^{2}-\left(\hbar \omega_{L}\right)^{2}}
$$

where $E_{G}$ is the band gap of silicon, an approximation for the energy difference between the donor states and the valence band at the conduction band minimum, and $\hbar \omega_{L}$ is the energy of the incoming light.

Figure 2 also includes the wavenumber dependent terms in Equation $1\left(\omega_{L}, \omega_{R}\right.$ and $\left.R_{12}\right)$ on top of the scattering volume. The resonant enhancement at the direct band gap $(3.4 \mathrm{eV})$, while a factor of 1000 gain $^{1}$ is still not enough to compensate for the reduction in scattering volume compared to the NIR.

Another process affecting the observation of ERS is the electron-hole pairs produced by above free-exciton edge illumination. The small penetration depth in the visible and UV would produce a high density hot electron-hole plasma. The impurities of interest could be ionised or screened by this plasma, greatly reducing the number of scattering centres. PL would still be observed from deeper in the sample where the carriers have diffused and thermalised, but ERS could only occur within the penetration depth of the laser. The NIR laser is not absorbed strongly enough to produce the plasma. So even if instrumentation has improved enough to observe the scattered light from above gap excitation, the production of this hot electron-hole plasma would still make it difficult to observe the ERS signal and use it as a local probe of donor interactions.

The presence of the donor excitonic transitions leads to the possibility of a resonance enhancement to the ERS when using an excitation source close to the energy of these real 


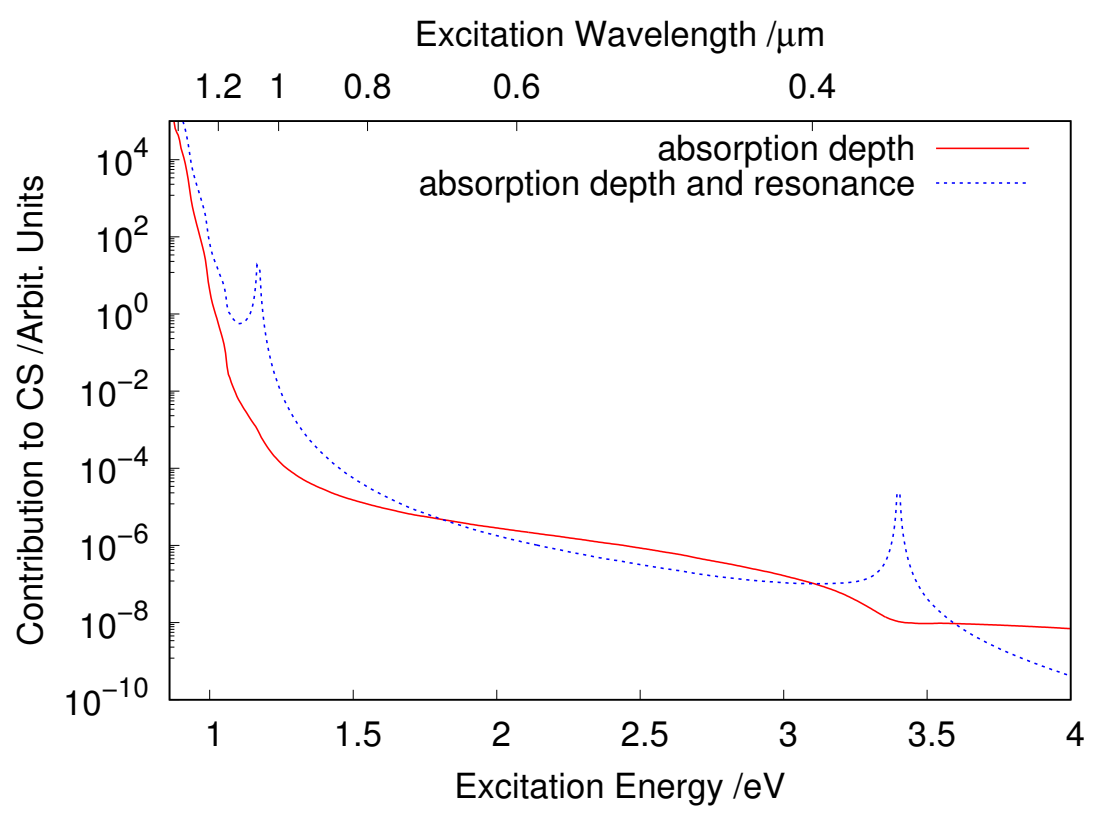

FIG. 2: Semi-log plot showing contribution to the electronic Raman scattering cross section due to the absorption depth of the laser excitation ${ }^{26}$ (solid line) and also including the resonance enhancement of the signal at energies close to the direct $(3.4 \mathrm{eV})$ and indirect $(1.17 \mathrm{eV})$ band gap of Si (dotted line). See text for details.

excitonic transitions ${ }^{1}$, the strongest of which are the luminescence transitions in the near infra red. While silicon has an indirect band gap and most excitons recombine with the aid of a phonon, the presence of the dopant atom breaks the crystal symmetry allowing for a direct transition between the valence band and the dopant bound exciton complex. We observe this transition as PL, labelled the No Phonon (NP) transition in Fig 1 and Table S1. As this state can also be formed in absorption, and has a very narrow linewidth when observed in isotopically enriched $\mathrm{Si}-28^{28}$, there is the possibility of a strong ERS resonance close to the energy of this transition. Though the competition between the production of bound excitons and ERS would need to be considered.

\section{Impurity Concentration Effects}

Previously, Jain et al. ${ }^{8}$ studied systematically the concentration broadening of ERS in Si:P due to donor-donor interactions. They observed a broadening, towards lower energies then a shift in the same direction with increasing concentration. The effects of these interactions 
began at concentrations above $3 \times 10^{17} \mathrm{~cm}^{-3}$. Here, using our measurements in the NIR, we extend this to include $\mathrm{Sb}$, As and B, but with the caveat that our samples don't cover the full range of concentrations for each impurity. With all the shallow impurities having similar binding energies and wavefunction extent, we will make some generalisations about their behaviour with concentration.

Figure 3 (a) shows the spectra from samples doped with donors (P, Sb, As) in order of increasing doping density. Various phosphorus doped samples with doping levels up to $\sim 1 \times 10^{17} \mathrm{~cm}^{-3}$ were measured. The general trend in this data is towards an increase in the intensity of the ERS peak (at $105 \mathrm{~cm}^{-1}$ ) with an increase in doping density. The lowest doping level from which ERS was observed was from the sample doped at $1.4 \times 10^{15} \mathrm{~cm}^{-3}$. For the available phosphorus doped samples the highest concentrations measured do not contain a significant proportion of donors with overlapping wavefunctions and the linewidth had not noticeably broadened, in agreement with the previous literature ${ }^{8}$.

The two Sb doped samples had a higher doping density than our P doped samples. For the sample Sb-A $\left(4 \times 10^{17} \mathrm{~cm}^{-3}\right)$, the Sb ERS peak position at $98 \mathrm{~cm}^{-1}$ matches that for isolated Sb donors and includes an "extended tail" towards lower energies as a consequence of donor-donor interactions. A reminder that the random nature of the doping can include both isolated and interacting donors. In addition to peak broadening, the centre of the ERS transition for sample Sb-B $\left(2 \times 10^{18} \mathrm{~cm}^{-3}\right)$ shifted to $94 \mathrm{~cm}^{-1}$, a comparable shift to that observed previously in $\mathrm{Si}: \mathrm{P}$ at a similar concentration. Both these sample had a concentration below the metal-insulator transition $(\mathrm{MIT})\left(\sim 3 \times 10^{18} \mathrm{~cm}^{-3}\right)$.

The arsenic doped sample had a concentration an order of magnitude above the MIT, at $2 \times 10^{19} \mathrm{~cm}^{-3}$. The spectrum includes what could be a broad ERS peak centred at $123 \mathrm{~cm}^{-1}$. This is a significant shift from the ERS peak of isolated As donors at $180 \mathrm{~cm}^{-1}$, the anticipated position of which is marked by an arrow in Figure 3 (a).

While we only measured one As doped sample making it is difficult to identify this peak as ERS, the characteristics of the peak do fit in with the broadening and shifting to lower energy trend expected for donors. At these concentrations above the MIT, ERS was observed in $\mathrm{Si}: \mathrm{P}^{8}$ as a continuum state at low energies with no clear peak. In Ge:As, there was a case where a clear but broad ERS peak was observed ${ }^{12}$ above the MIT, though not as far past it as our data. The peak is also unlikely to be a PL feature as those peaks were observed to shift in the opposite direction with increasing concentration. It could be a new phonon 

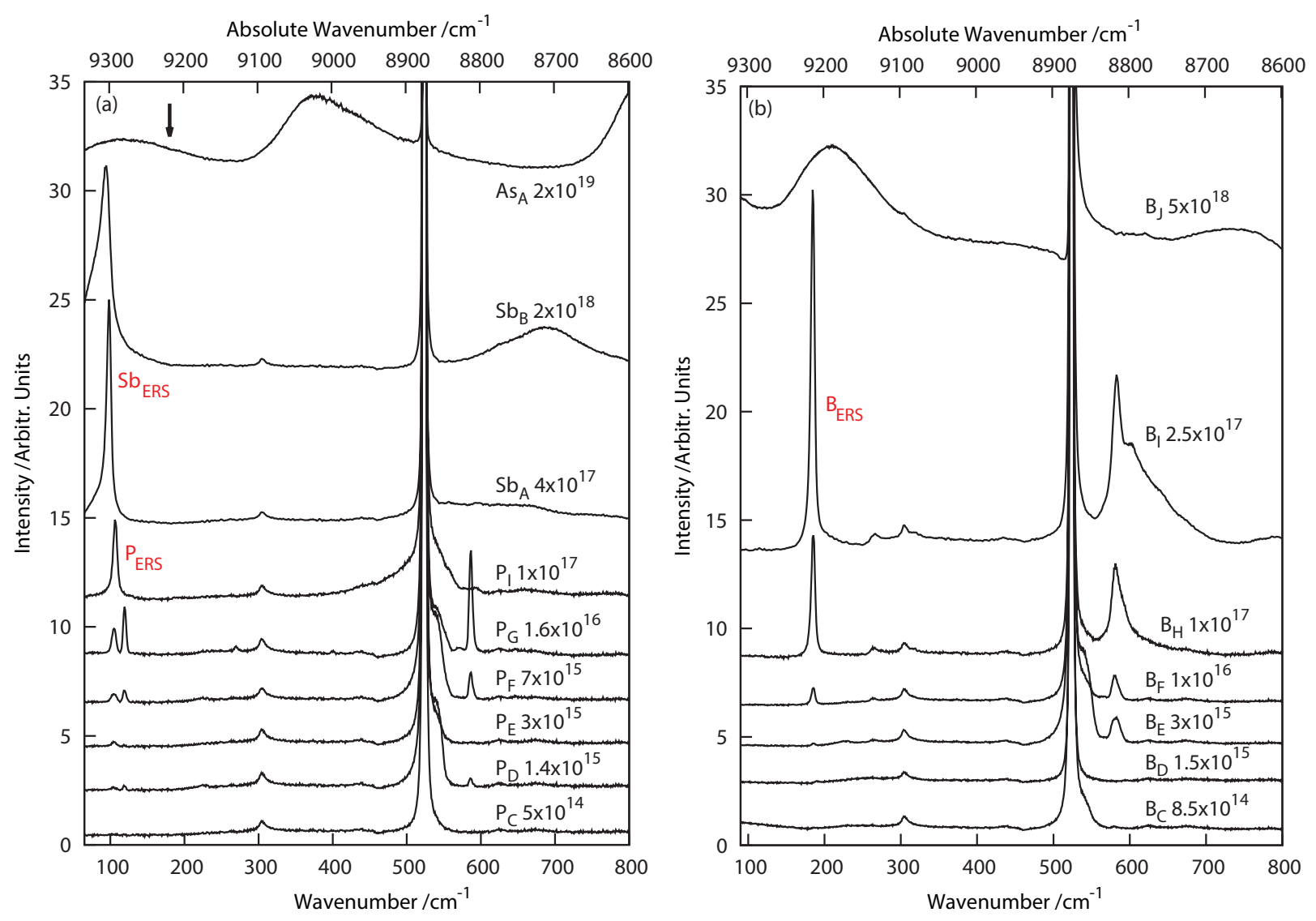

FIG. 3: Near infra-red measurements taken from (a) donor doped, and (b) acceptor (boron) doped silicon samples at various doping concentrations. Spectra have been displaced vertically for clarity, labelled with the sample identification and the centre of the calculated doping concentration range (in $\mathrm{cm}^{-3}$ ), per Table I. The arrow in (a) indicates the expected position of the As ERS line for isolated donors.

band, though it was only observed at low temperatures. Further study of the formation of the impurity band with concentration for the individual donor species is warranted.

The spectra from our various boron doped silicon samples are shown in Figure 3 (b), stacked in order of lowest concentration at the bottom of the figure, to highest at the top. The lowest B concentration from which an ERS transition could be observed was from a sample with $1.5 \times 10^{15} \mathrm{~cm}^{-3} \mathrm{~B}$ acceptors. This value closely matched the lowest concentration ERS signal observed from $\mathrm{P}$ doped silicon, indicating the scattering cross section from the two species is of the same order of magnitude. The intensity of the ERS peak increased with doping density. Up to a concentration of $1 \times 10^{17} \mathrm{~cm}^{-3}$ no broadening or peak shift could be resolved. From $2.5 \times 10^{17} \mathrm{~cm}^{-3}$ the peak started to broaden asymmetrically with 
a tail to higher energies, which is in the opposite direction to the donor case. Interactions between acceptors started at a concentration similar to the case of the donors.

The highest concentration boron doped sample $\left(\sim 5 \times 10^{18} \mathrm{~cm}^{-3}\right)$, just above the MIT, shows a broad ERS peak shifted to higher energies, with the centre of the peak at $210 \mathrm{~cm}^{-1}$. Again, this shift is in the opposite direction to that observed in donors. A broad but clear peak above but close to the MIT is not unexpected given the random nature of the doping. Small clusters of impurities can coexist with a continuum metallic state ${ }^{29,30}$, providing states for the ERS transition. While this peak could also be a new phonon feature, it was only observed at low temperatures. Measurements of more samples with concentrations around the MIT would be required to confirm this trend.

The beginnings of another broad peak can be observed starting at $120 \mathrm{~cm}^{-1}$ towards lower energies indicating scattering from a continuum of electronic states (i.e. where the wavefunctions of many acceptors overlap), similar to previous observations in highly $\mathrm{P}$ doped Si samples ${ }^{8}$. The continuum of electronic states present in highly doped samples can interact with the discrete state of the Si TO phonon producing a Fano type resonance ${ }^{31,32}$, which is evident as an asymmetry in the TO phonon peak. This feature is observed in Figure 3 (b) for sample B-J, the highest B doping, as an anti-resonance at $515 \mathrm{~cm}^{-1}$ on the left hand side of the TO peak, but does not show up in the highly doped donor samples.

\section{Acceptor interactions}

The ERS transition from acceptors occurs between the $1 s$ like states of the acceptor associated with the spin-orbit split valence band, $\Gamma_{8}^{+}\left(1 S p_{3 / 2}\right)$ to $\Gamma_{7}^{+}\left(1 S p_{1 / 2}\right)$. The valence band splitting is $44 \mathrm{meV}$ and this reduces to $23.4 \mathrm{meV}$ for the associated boron acceptor states due to band structure effects. Effective mass approximation calculations for acceptors in Si have shown a decrease in the spin-orbit splitting with an increase of the acceptor binding energy, matching experimental observations for various acceptor species ${ }^{13,14}$. In analogy with the case of the donors, where the influence of the chemical shift of the donor ground state is reduced for interacting donors, a case could be made that the presence of the acceptor reduces the influence of the spin-orbit splitting. For interacting acceptors, as the hole is shared between two or more acceptors and spends less time close to the impurity core, the associated acceptor states move closer in energy separation to the spin-orbit splitting of the 
valence band. This would be observed as an increase in the energy separation of the acceptor states.

\section{ERS peak energy shift}

The shift in energy of the ERS peak from the isolated impurity position plotted against the mean nearest neighbour separation is shown in Figure 4. Due to the random nature of the doping, the mean nearest neighbour separation is calculated from the impurity concentration using $^{24}: r^{*}=0.554 n^{-1 / 3}$. The data from Jain et al. ${ }^{8}$ is included, and matches well with our data. The different direction of the shift between donor and acceptors is clear. To first order the trend in energy shift with separation, including all shallow dopants in our study, can be modelled using an exponential function similar to the hydrogenic nature of the impurity wave function:

$$
E(r)=-A \exp \left[\frac{-2 r}{a^{*}}\right]
$$

where $r$ is the mean separation between two dopants, $A$ is the binding energy and $a^{*}$ is the Bohr radius of the donor or acceptor. $E(r)$ represents the hydrogenic wavefunction of the impurity state and the overlap with its neighbor. The reported binding energies of the impurities studied here are, P: 45.6, Sb: 42.7, As: 53.8, and B: $45.7 \mathrm{meV}^{17}$. Since each of these dopants is considered energetically shallow and to allow for comparison, we have used values of $A=45.6 \mathrm{meV}$ and $a^{*}=2.5 \mathrm{~nm}$ (i.e. for $\mathrm{P}^{17}$ ) for Figure 4 . Note that no fitting routine was used. To fully characterise the interaction the chemical shifts for each dopant should also be taken into account as well as including interactions between more than two impurities, which have not been done in this work.

The trend line plotted in Figure 4 defines a model of wavefunction overlap between neighboring impurities which is based on the measured data with mean dopant separations of less than $5 \mathrm{~nm}$. We note however, that weaker exchange interactions can also occur when mean separations are greater than $5 \mathrm{~nm}$. For these larger dopant spacing, shifts arising from wavefunction interactions are less likely to be experimentally observed as they require greater spectral resolution and photon detection sensitivity than we had. 


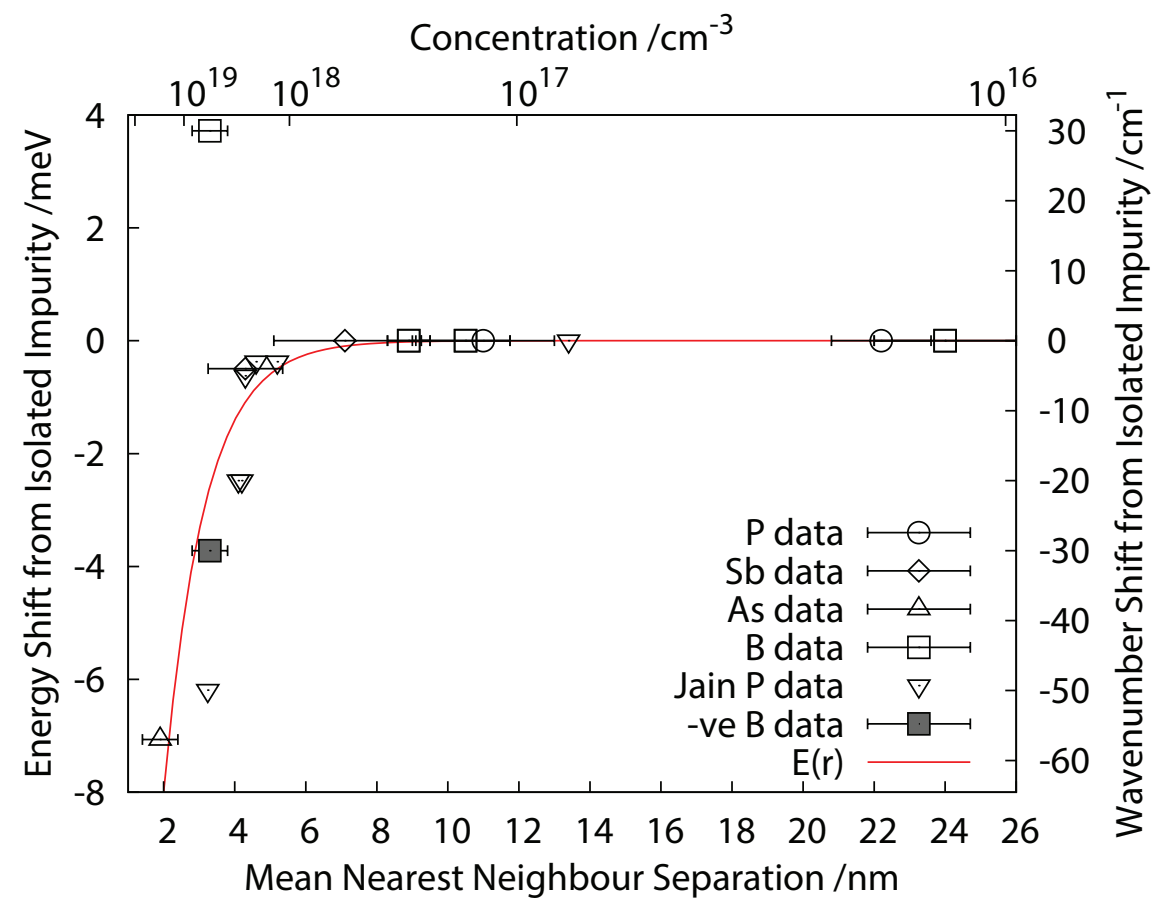

FIG. 4: The shift in ERS peak centre energy from isolated impurity ERS peak energy plotted against the mean nearest neighbor separation. The line $E(r)$ represents Equation 3 and follows the exponential form of the impurity wavefunction envelope. The error bars indicate the uncertainty in the measured resistivity of the samples. The uncertainty in energy shift is smaller than the size of the plotted symbols. The solid symbol indicates the inverse of the energy shift of the only non-zero shift B acceptor ERS line position, to make it easier to compare with the donors. See text for conversion between concentration and mean nearest neighbour separation. Jain Si:P data from Reference ${ }^{8}$.

\section{CONCLUSION}

In this work we report measurements of electronic Raman scattering spectroscopy from a range of dopants in silicon. The dopant ensembles of varying concentrations all arose from bulk doping processes and were successfully identified using the ERS technique, reestablishing NIR ERS as a valuable tool for dopant spectroscopy in Si.

In contrast to the NIR measurements, no ERS was observed using visible wavelength excitation. This was likely due to the smaller penetration depth of the light for excitation energies above the indirect band gap of Si, leading to a smaller scattering volume and the production of a hot electron-hole plasma. Observation with UV excitation would be difficult 
as the resonance enhancement in the UV may not increase the sensitivity enough. This limits the ability to use ERS as a localised probe of shallow donors and acceptors in Si. We propose the possibility of a resonant enhancement with the direct impurity excitonic transition, which also occurs in the NIR.

We report the concentration dependence of the ERS peak from $\mathrm{P}, \mathrm{Sb}$, and As donors in silicon which was shown to match the trend previously reported for $\mathrm{P}$, a broadening of the peak with a shift to lower energies. In the case of acceptors, the shift is in the opposite direction to that of the donors, an increase in the energy of this transition, which we propose is due to sharing of the bound hole state by two or more acceptors, which reduces the influence of the acceptor core on the splitting of the orbital states. To first order, and ignoring the impurity chemical shift, the magnitude of the shift of the ERS peak with increasing dopant concentration follows the exponential form of the wavefunction overlap of neighboring impurities.

\section{Acknowledgments}

This work was supported by the Australian Research Council Centre of Excellence for Quantum Computer Technology. NS would like to thank B.C. Johnson for useful discussions.

* Present address: Melbourne Centre for Nanofabrication, Clayton VIC 3168, Australia

$\dagger$ Electronic address: s.prawer@unimelb.edu.au

1 B. Koiller, X. Hu, H. D. Drew, S. Das Sarma, Phys. Rev. Lett. 2003, 90, 067401.

2 B. E. Kane, Nature 1998, 393, 133.

3 R. Loudon, Adv. Phys. 1964, 13, 423.

${ }^{4}$ R. J. Elliot, R. Loudon, Phys. Lett. 1963, 3, 189.

5 C. Weisbuch, R. Ulbrich, Resonant Light Scattering Mediated by Excitonic Polaritons in Semiconductors, Light Scattering in Solids III, Topics Appl. Physics 51, Springer, Berlin, 1982, pp. $205-263$.

6 R. G. Ulbrich, N. Van Hieu, C. Weisbuch, Phys. Rev. Lett. 1981, 46, 53.

7 G. B. Wright, A. Mooradian, Phys. Rev. Lett. 1967, 18, 608. 
8 K. Jain, S. Lai, M. V. Klein, Phys. Rav. B 1976, 13, 5448.

9 J. M. Cherlow, R. L. Aggarwal, B. Lax, Phys. Rev. B 1973, 7, 4547.

10 P. J. Colwell, M. V. Kline, Phys. Rev. B 1972, 6, 498.

11 J. Doehler, Phys. Rev. B 1975, 12, 2917.

12 J. Doehler, P. J. Colwell, S. A. Solin, Phys. Rev. Lett. 1975, 34, 584.

13 J. Serrano, M. Cardona, T. Ruf, Solid State Commun. 2000, 113, 411.

14 J. Serrano, A. Wysmolek, T. Ruf, M. Cardona, Phys. B 1999, 273-274, 640.

15 S. G. Pavlov, H.-W. Hübers, U. Böttger, R. K. Zhukavin, V. N. Shastin, J. N. Hovenier, B. Redlich, N. V. Abrosimov, H. Riemann, Appl. Phys. Lett. 2008, 92, 091111.

16 S. G. Pavlov, U. Böttger, J. N. Hovenier, N. V. Abrosimov, H. Riemann, R. K. Zhukavin, V. N. Shastin, B. Redlich, A. F. G. van der Meer, H.-W. Hübers, Appl. Phys. Lett. 2009, 94, 171112. 17 A. K. Ramdas, S. Rodriguez, Rep. Prog. Phys. 1981, 44, 1297.

18 M. V. Klein, Electronic Raman Scattering, Light Scattering in Solids I, Topics Appl. Physics 8, Springer, Berlin, 1975, pp. 147-204.

19 H. R. Chandrasekhar, A. K. Ramdas, S. Rodriguez, Phys. Rev. B 1975, 12, 5780.

20 K. J. Morse, R. J. S. Abraham, D. P. Franke, N. V. Abrosimov, M. L. W. Thewalt, Phys. Rev. B 2016, 93, 125207.

21 M. L. W. Thewalt, Can. J. Phys. 1977, 55, 1463.

22 G. Davies, Phys. Rep. 1989, 176, 83.

23 J. C. Irvin, S. M. Sze, Solid-State Electron. 1968, 11, 599.

24 S. Chandrasekhar, Rev. Mod. Phys. 1943, 15, 1.

25 M. L. W. Thewalt, W. G. McMullan, Phys. Rev. B 1984, 30, 6232.

26 M. A. Green, M. J. Keevers, Prog. Photovoltaics 1995, 3, 189.

27 W. Kohn, Solid State Phys. 1957, 5, 257.

28 A. Yang, M. Steger, D. Karaiskaj, M. L. W. Thewalt, M. Cardona, K. M. Itoh, H. Riemann, N. V. Abrosimov, M. F. Churbanov, A. V. Gusev, et al., Phys. Rev. Lett. 2006, 97, 227401.

29 P. P. Altermatt, A. Schenk, G. Heiser, J. Appl. Phys. 2006, 100, 113714.

30 P. P. Altermatt, A. Schenk, B. Schmithüsen, G. Heiser, J. Appl. Phys. 2006, 100, 113715.

31 F. Cerdeira, T. A. Fjeldly, M. Cardona, Phys. Rev. B 1973, 8, 4734.

32 B. G. Burke, J. Chan, K. A. Williams, Z. Wu, A. A. Puretzky, D. B. Geohegan, J. Raman Spectrosc. 2010, 41, 1759. 


\begin{tabular}{ccccc}
\hline \hline Name & Dopant & $\rho$ & $n$ & $r^{*}$ \\
& & Ohm-cm & $c m^{-3}$ & $n m$ \\
\hline P-C & P & $7.7-15$ & $2.9 \times 10^{14}-5.8 \times 10^{14}$ & $84-66$ \\
P-D & P & $2.5-4$ & $1.1 \times 10^{15}-1.8 \times 10^{15}$ & $54-46$ \\
P-E & P & $1-2$ & $2.3 \times 10^{15}-4.8 \times 10^{15}$ & $42-33$ \\
P-F & P & $0.5-0.9$ & $5.4 \times 10^{15}-1 \times 10^{16}$ & $32-26$ \\
P-G & P & $0.3-0.4$ & $1.3 \times 10^{16}-1.9 \times 10^{16}$ & $24-21$ \\
P-I & P & $0.05-0.1$ & $7.8 \times 10^{16}-2.3 \times 10^{17}$ & $13-9$ \\
Sb-A & Sb & $0.02-0.05$ & $2.3 \times 10^{17}-1.2 \times 10^{18}$ & $9-5.2$ \\
Sb-B & Sb & $0.01-0.02$ & $1.2 \times 10^{18}-4.4 \times 10^{18}$ & $5.2-3.4$ \\
As-A & As & $0.001-0.005$ & $1.2 \times 10^{19}-7.4 \times 10^{19}$ & $2.4-1.3$ \\
B-C & B & $14-17$ & $7.7 \times 10^{14}-9.4 \times 10^{14}$ & $60-57$ \\
B-D & B & $8-12$ & $1.1 \times 10^{15}-1.7 \times 10^{15}$ & $54-46$ \\
B-E & B & $4-8$ & $1.7 \times 10^{15}-3.4 \times 10^{15}$ & $46-37$ \\
B-F & B & $1-1.5$ & $9.5 \times 10^{15}-1.5 \times 10^{16}$ & $26-22$ \\
B-G & B & $0.81-0.95$ & $1.6 \times 10^{16}-1.9 \times 10^{16}$ & $22-21$ \\
B-H & B & $0.1-0.2$ & $9.6 \times 10^{16}-2.4 \times 10^{17}$ & $12-9$ \\
B-I & B & $0.092-0.108$ & $2.2 \times 10^{17}-2.7 \times 10^{17}$ & $9.2-8.6$ \\
B-J & B & $0.01-0.02$ & $2.7 \times 10^{18}-8 \times 10^{18}$ & $4-2.8$ \\
\hline \hline & & & & 2.8 \\
\hline
\end{tabular}

TABLE I: List of the bulk doped silicon samples studied in this work. Resistivity $(\rho)$ as quoted by manufacturer, doping density $(n)$ calculated via Reference ${ }^{23}$, and mean nearest-neighbour separation $\left(r^{*}\right)$ calculated as per Reference ${ }^{24}$, where $r^{*}=0.554 n^{-1 / 3}$. 
Electronic Raman scattering (ERS) is investigated as a probe for interactions between impurities in silicon, studying $\mathrm{P}, \mathrm{Sb}$ and $\mathrm{As}$ donors and $\mathrm{B}$ acceptors at various concentrations. The difficulties of using ERS as a localised probe with above band gap excitation are discussed. We demonstrate that the perturbation of the ERS transition energy resulting from wavefunction overlap of nearest neighbours is opposite for donors and acceptors.

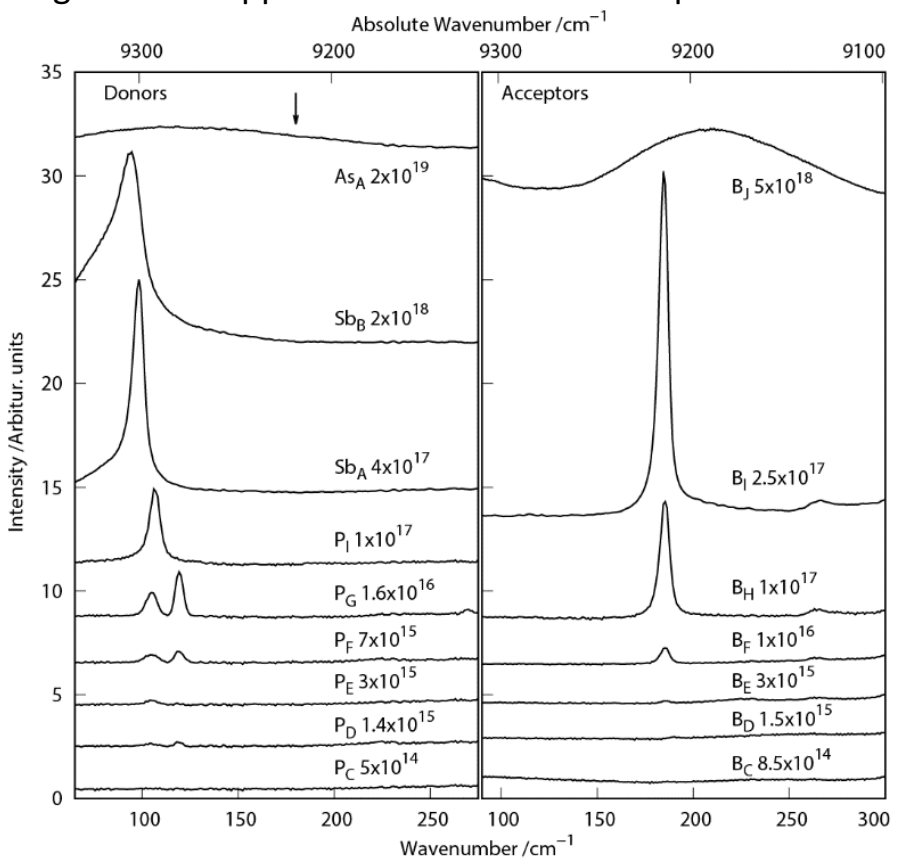

Nikolas Stavrias, Paul G. Spizzirri, Steven Prawer. 

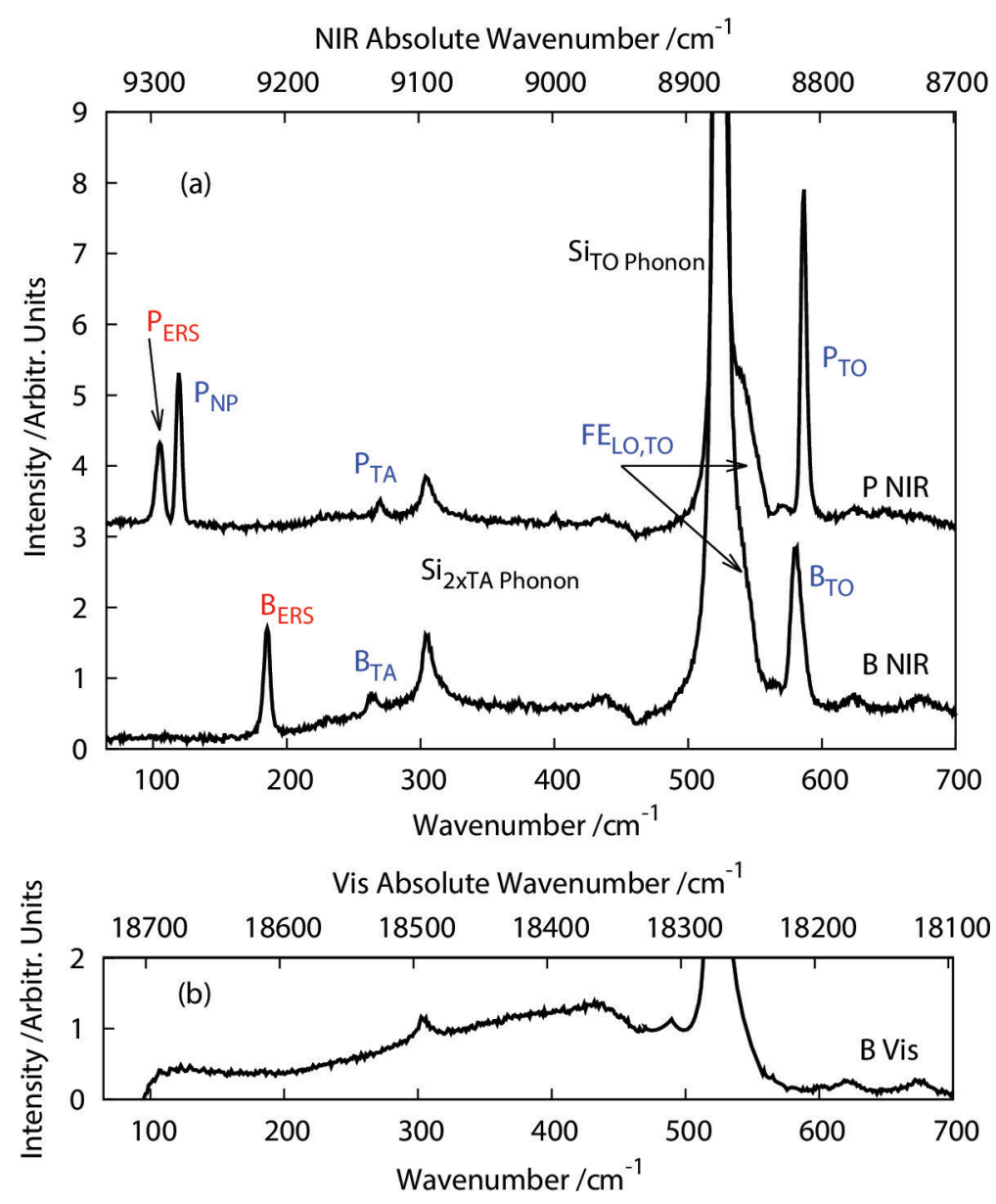

jrs-fig1-combined-wn.eps 


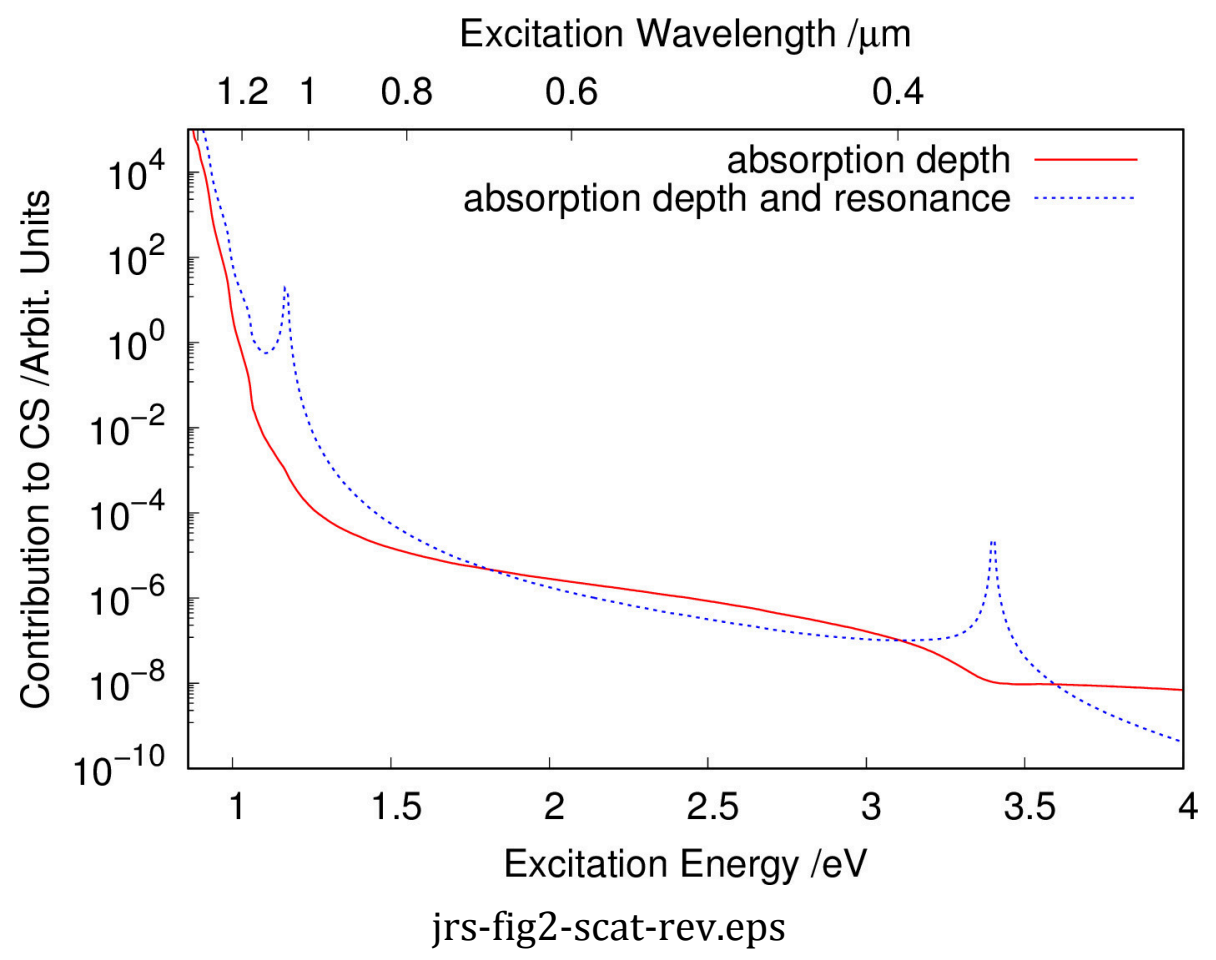

This article is protected by copyright. All rights reserved. 


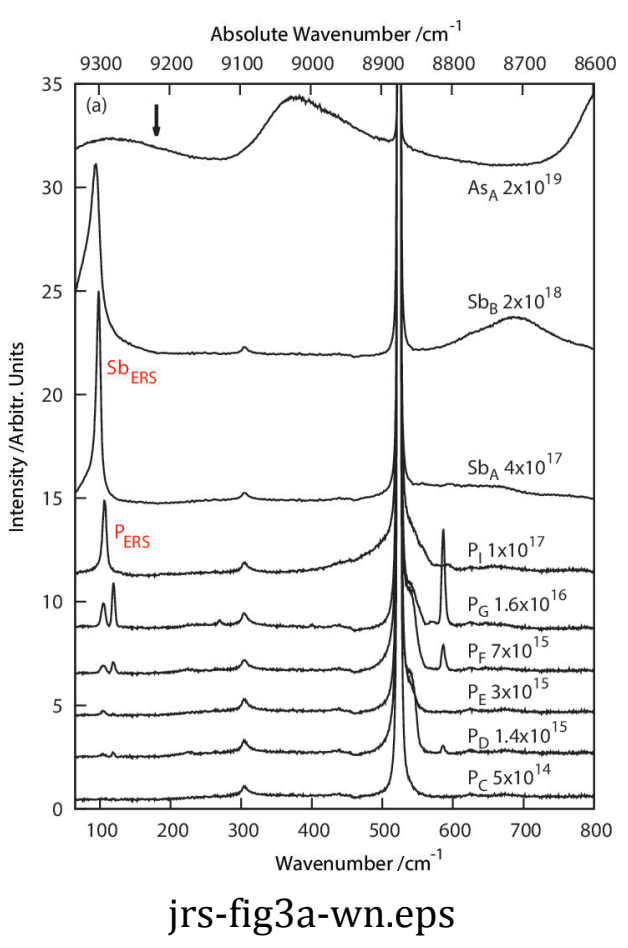

This article is protected by copyright. All rights reserved. 


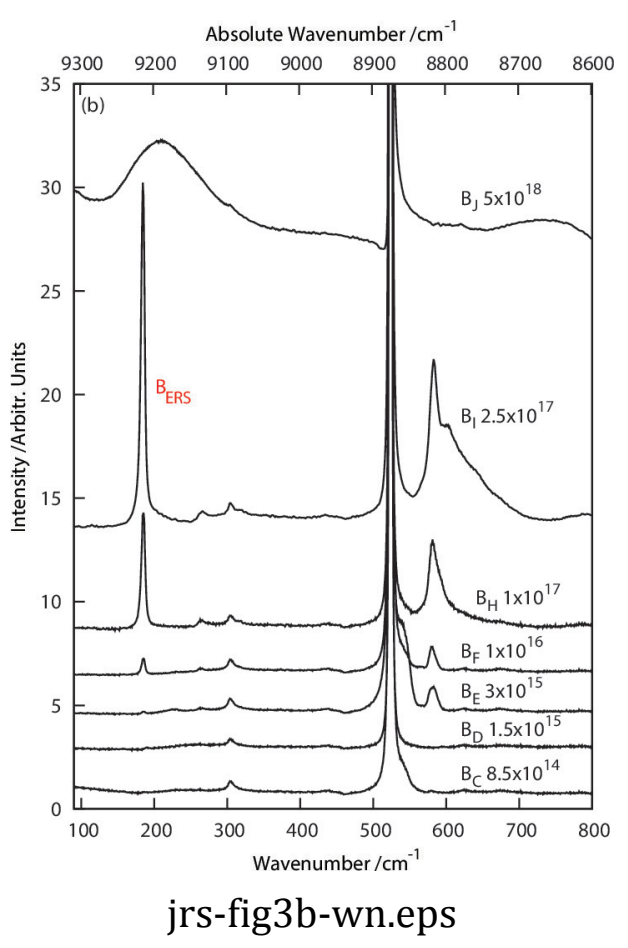

This article is protected by copyright. All rights reserved. 


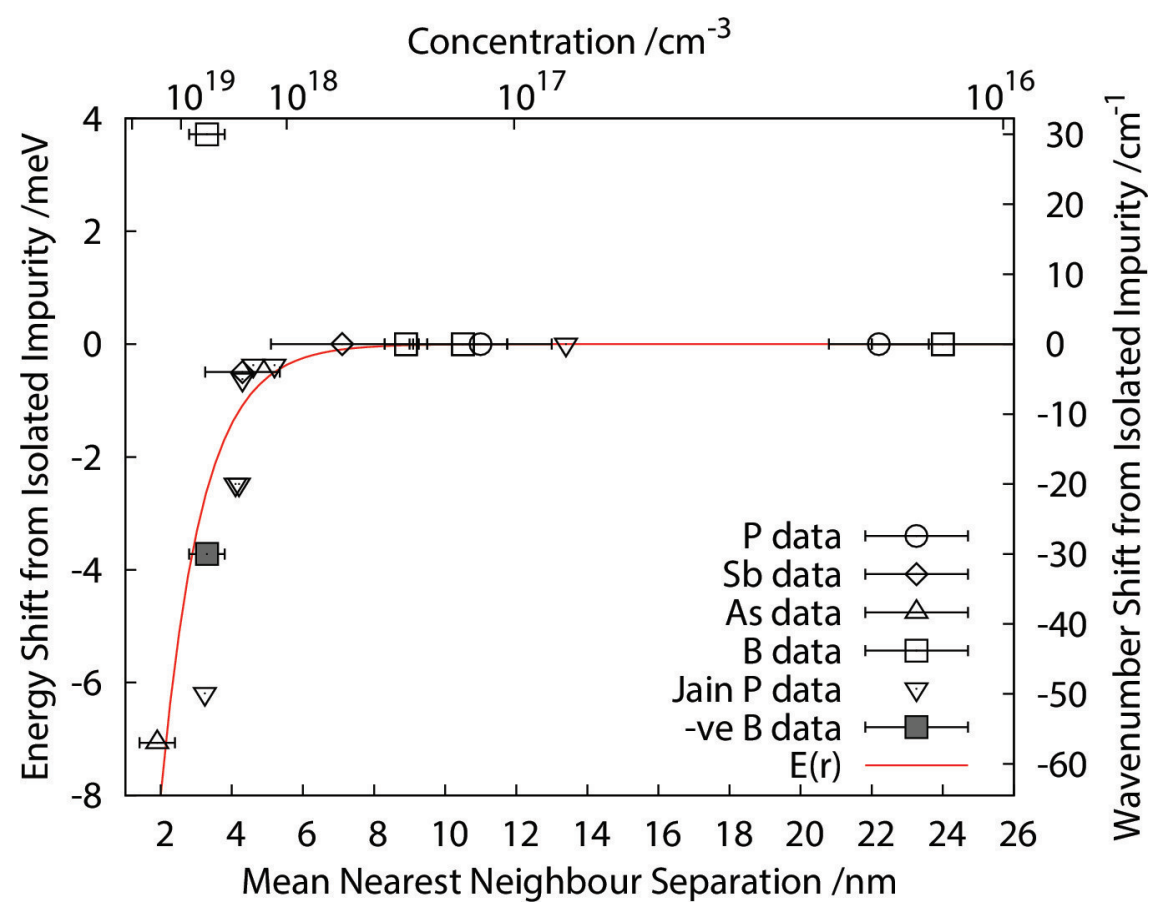

jrs-shift-fit.eps

This article is protected by copyright. All rights reserved. 


\section{COPYRIGHT TRANSFER AGREEMENT}

Date $5 / 1012018$ contributorname NIKCLAS STAVRIHS

Contributoraddress: SCHOOL of PHYSICS WNWERSIY OFMELROURNE, AUST RALIA

Manuscript number (if known): JRS - I8-0224

REManuscriptentitled ELECTRONIC RAMAN SCATTERING AS A PROBE FOR

INVESTIGATINS INTERACTIONS BETWEEN IMPURITIES IN SILLDA ithe "Contribution")

for publication in JOURNAL OF RAMAN SPLC IROSCOPY (the "Journal"

published by WILEY BLACKWEU ("Wiley-Blackwell")

Dear Contributor(s):

Thank you for subrritting your Contribution for publication. In order to expedite the editing and publishing process and enable Wiley-Blackwell to disseminate your Contribution to the fullest extent, we need to have this Copyright Transfer Agreement signed and returned as directed in the Journal's instructions for authors as soon as possible. If the Contribution is not accepted for publication, or if the Contribution is subsequently rejected, this Agreement shall be null and void. Publication cannot proceed without a signed copy of this Agreement.

\section{A. COPYRIGHT}

1. The Contributor assigns to Wiley-Blackwell, during the full term of copyright and any extensions or renewals, all copyright in and to the Contribution, and all rights therein, including but not limited to the right to publish, republish, transmit, sell, distribute and otherwise use the Contribution in whole or in part in electronic and print editions of the Journal and in derivative works throughout the world, in all languages and in all media of expression now known or later developed, and to license or permit others to do 50.

2. Reproduction, posting, transmission or other distribution or use of the final Contribution in whole or in part in any medium by the Contributor as permit. ted by this Agreement requires a citation to the Journal and an appropriate credit to Wiley-Blackwell as Publisher, and/or the Society if applicable, suitable in form and content as follows: (Title of Article, Author, Journal Title and Volume/ssue, Copyright @ lyearl, copyright owner as specified in the Journal). Links to the final anticle on Wiley-Blackwell's website are encouraged where appropriate.

\section{B. RETAINED RIGHTS}

Notwithstanding the above, the Contributor or, if applicable, the Contributor's Employer, retains all proprietary rights other than copyright, such as patent rights, in any process, procedure or article of manufacture described in the Contribution

\section{PERMITTED USES BY CONTRIBUTOR}

1. Submitted Version. Wiley-Blackweil licenses back the following rights to the Contributor in the verssion of the Contribution as originally submitted for publication:

a. After publication of the final article, the right to self-archive on the Contributor's personal intranet page or in the Contributor's institution's/employer's institutional intranet repository or archive. The Contributor may not update the submission version or replace it with the published Contribution. The version posted must contain a legend as follows. This is the pre-peer reviewed version of the following article: FUL CITE, which has been published in final form at [Link to final article].

b. The right to transmit, print and share copies with colleagues.

2. Accepted Version. Reuse of the accepted and peer-reviewed (but not final) version of the Contribution shall be by separate agreement with WileyBlackwell. Wiley-Blackwell has agreements with certain funding agencies governing reuse of this version. The details of those relationships, and other offerings allowing open web use are set forth at the following website: htto:/Awww.wiley com/go/funderstatement. NIH grantees should check the box at the bottom of this document.
3. Final Published Version, Wiley-Blackwell hereby licenses back to the Contributor the following rights with respect to the final published version of the Contribution

a. Copies for colleagues. The personal right of the Contributor only to send or transmit individual copies of the final published version to colleagues upon their specific request provided no fee is charged, and further-provided that there is no systematic distribution of the Contribution, e,g posting on a listserve, website or automated delivery. For those Contributors who wish to send high-quality e-prints, purchase reprints, or who wish to distribute copies more broadly than allowed hereunder (e.g. to groups of colleagues. or mailing lists), please contact the publishing office.

b. Re-use in other publications. The right to re-use the final Contribution or parts thereof for any publication authored or edited by the Contributor (excluding journal articles) where such re-used material constitutes less than half of the total material in such publication. In such case, any modift: cations should be accurately noted.

c. Teaching duties. The right to include the Contribution in teaching or training duties at the Contributor's irstitution/place of employment induding in course packs, e-reserves, presentation at professional conferences, in-house training, of distance learning. The Contribution may not be used in seminars outside of normal teaching obligations (e.g. commercial seminars). Electronic posting of the final published version in connection with teaching/training at the Contributor's institution/place of employment is permitted subject to the implementation of reasonable access control mechanisms, such as user name and password. Posting the final published version on the open Internet is not permitted.

d. Oral presentations. The right to make oral presentations based on the Contribution.

4. Article Abstracts, Figures, Tables, Data Sets, Artwork and Selected Text (up to 250 words).

a. Contributors may re-use unmodified abstracts for any non-commencial purpose. For on-line uses of the abstracts, Wiley-Blackwell encourages but does not require linking back to the final published versions.

b. Contributors may re-use figures, tables, data sets, artwork, and selected text up to 250 words from their Contributions, provided the following concitions are met:

(i) Full and accurate credit must be given to the Contribution.

(iii) Modifications to the figures, tables and data must be noted Otherwise, no changes may be made.

(iii) The reuse may not be made for direct comimercial purposes, or tor firiancial consideration to the Contributor

(iv) Nothing herein shall permit dual publication in violation of joumal ethical practices 


\section{CONTRIBUTIONS OWNED BY EMPLOYER}

1. If the Contribution was written by the Contributor in the course of the Contributor's employment las a "work-made-for-hire" in the course of emplayment), the Contribution is owned by the company/employer which must sign this Agreement (in addition to the Contributor's signature) in the space provided below. In such case, the company/emplover hereby assigns to Wiley-Blackwell, during the full term of copyright, all copyright in and to the Contribution for the full term of copyright throughout the world as specified in paragraph A above.

2. In addition to the rights specified as retained in paragraph $B$ above and the rights granted back to the Contributor pursuant to paragraph C above. WileyBlackwell hereby grants back, without charge, to such company/employer, its subsidiaries and divisions, the right to make copies of and distribute the final published Contribution internally in print format or electronically on the Company's internal network. Copies so used may not be resold or distributed externally. However the campany/employer may include information and text from the Contribution as part of an information package induded with software or other products offered for sale or license or included in patent applications. Posting of the final published Contribution by the institution on a public access website may only be done with Wiley-Blackwell's written permission, and payment of any applicable fee(s). Also, upon payment of Wiley-Blackwell's reprint fee, the institution may distribute print copies of the published Contribution externally.

\section{E. GOVERNMENT CONTRACTS}

In the case of a Contribution prepared under U.S. Government contract or grant, the U.S. Government may reproduce, without charge, all or portions of the Contribution and may authorize others to do so, for official U.S. Govern- ment purposes only, if the U.S. Government contract or grant so requires, (U.S Government, U,K Government, and other government employees: see notes at end.)

\section{F. COPYRIGHT NOTICE}

The Contributor and the company/employer agree that any and all copies of the final published version of the Contribution or any part thereof distributed or posted by them in print or electronic format as permitted herein will include the notice of copyright as stipulated in the Journal and a full citation to the journal as published by Wiley-Blackweifl

\section{G. CONTRIBUTOR'S REPRESENTATIONS}

The Contributor represents that the Contribution is the Contributor's original work, all individuals identified as Contributors actually contributed to the Contribution, and all individuals who contributed are included if the Contribution was prepared jointly, the Contributor agrees to inform the co-Contributors of the terms of this Agreement and to obtain their signature to this Agreement or their written permission to sign on their behalf. The Contribution is submittec only to this Journal and has not been published before. (If excerpts from copyrighted works owned by third parties are included, the Contributor will obtain written permission from the copyright owners for all uses as set forth in WileyBlackwell's permissions form or in the Journal's Instructions for Contributors, and show credit to the sources in the Contribution.) The Contributor also warrants that the Contribution contains no libelous or urlawful statements, does not infringe upon the rights (including without limitation the copyright, patent or trademark rights) or the privacy of others, or contain material or instructions that might cause harm or injury.

\section{CHECK ONE BOX:}

\section{$\checkmark$ Contributor-owned work} atTACM ADDITIONAL SIGNATURE PAGES AS NECESSARY

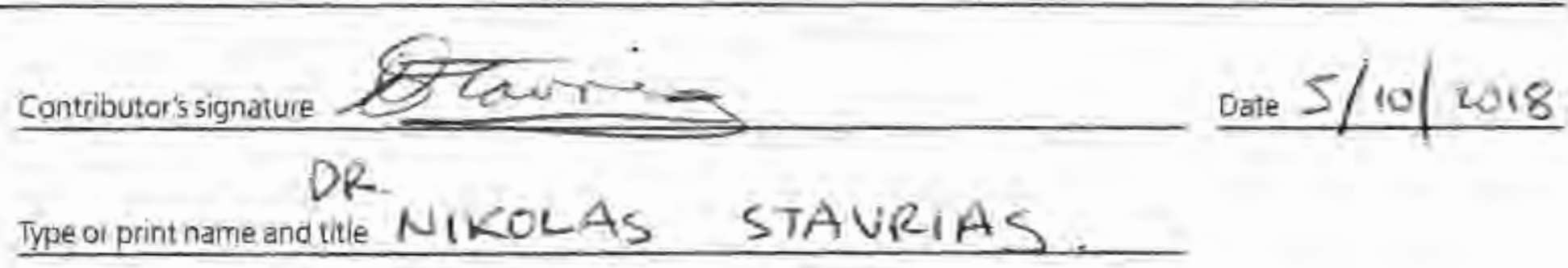

Co-contributor's signature

type or print name and title

Company/linstitution-owned waik

(made-for-hire in the

course of employment)

A contribution prepared by a U.S. federal government employee as part of the employee's official dufies, or which is an official U.5. Government publication, is called a "U.5. Government work, " and is in the public domain in the United States. In such case, the employee may cross out Paragraph A.) but mivst sign (in thie Contributor's signature line) and return this Agreement if the Contribution was not prepared as part of thie employee's duties or is not an official US. Goveminent publication, it is not a U S. Govemment work

U.K. Government work (Crown Copyright)

\section{Note to U.K. Government Employees}

The rights in a Contribution nrenared by an employee of a $U K$ government department, agenco or other Crown body as part of his/her officlal duties, or which is an ufficial government publication, belong to the krown. U.K. government authors should subinit a signed declaration form together with this Agreement. The form can be obtained via http//www. oosi.gov uk/advice/crown-copyright/copyright-guidance/ publication-of-articles-written-by-ministers-and-avib-ervantż-hur

Qther Government work

\section{Note to Non-U.S., Nan-U.K. Government Employees}

If your status as a government terioloyee legally prevents you from signing this Aageement. please contact the editorial office

\section{NiHGranteps}

Note to NiH Grantees

Pursuant to NiH mandate, Wiley-Blackwell Will post the accepted version of Contributions authered by WIH grant-holders to PubMed Central ugon acceptance This accepted version will be made publicily available 12 months after publication. For further intormation, see www. willey corrdgo/nilhmandate 


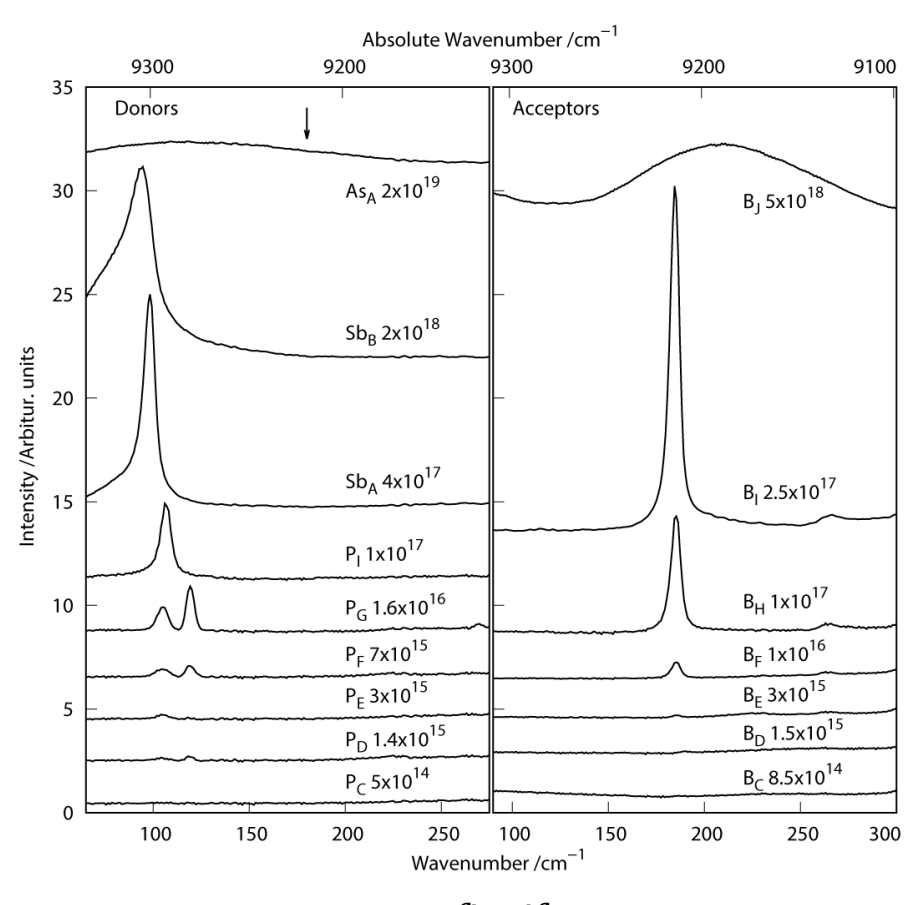

toc-fig.tif

This article is protected by copyright. All rights reserved. 


\section{University Library}

\section{- M M N E R VA A gateway to Melbourne's research publications}

Minerva Access is the Institutional Repository of The University of Melbourne

Author/s:

Stavrias, N;Spizzirri, PG;Prawer, S

Title:

Electronic Raman scattering as a probe for investigating interactions between impurities in silicon

Date:

2019-04-01

Citation:

Stavrias, N., Spizzirri, P. G. \& Prawer, S. (2019). Electronic Raman scattering as a probe for investigating interactions between impurities in silicon. JOURNAL OF RAMAN SPECTROSCOPY, 50 (4), pp.595-602. https://doi.org/10.1002/jrs.5543.

Persistent Link:

http://hdl.handle.net/11343/285248 